\title{
K Shell X-Ray Fluorescence Parameters of Some Elements in the Atomic Range $40 \leq Z \leq 50$
}

\author{
Pinar Onder, ${ }^{1}$ Ahmet Tursucu, ${ }^{2}$ and Demet Demir ${ }^{1}$ \\ ${ }^{1}$ Department of Physics, Faculty of Science, Atatürk University, 25240 Erzurum, Turkey \\ ${ }^{2}$ Department of Energy Systems, Faculty of Engineering, Sirnak University, 73000 Sirnak, Turkey
}

Correspondence should be addressed to Pinar Onder; pinar.onder@atauni.edu.tr

Received 8 July 2013; Accepted 20 August 2013

Academic Editor: Keith E. Holbert

Copyright (C) 2013 Pinar Onder et al. This is an open access article distributed under the Creative Commons Attribution License, which permits unrestricted use, distribution, and reproduction in any medium, provided the original work is properly cited.

\begin{abstract}
The production cross sections $\sigma_{\mathrm{K}_{i}}$, the fluorescence yield $W_{\mathrm{K}}$, K shell X-ray intensity ratio $I_{\mathrm{K}_{\beta}} / I_{\mathrm{K}_{\alpha}}$, the vacancy transfer probabilities from $\mathrm{K}$ to $\mathrm{L}$ shell $\eta_{\mathrm{KL}}$, and the $\Gamma_{\mathrm{K}}$ level widths for some elements in the atomic range $40 \leq Z \leq 50$ were measured. The samples were excited by $80.998 \mathrm{keV}$ gamma rays from a $10 \mathrm{mCi}^{133} \mathrm{Ba}$ radioactive source. The $\mathrm{KX}$-rays emitted by samples were detected by using a CdTe detector. These parameters have been theoretically calculated, also. The experimental values were compared with the theoretical and semiempirical values. Our experimental values closely agreed with theoretical values and other experimental values.
\end{abstract}

\section{Introduction}

Accurate experimental values of X-ray fluorescence parameters such as the production cross sections, the fluorescence yields, the intensity ratios, the vacancy transfer probabilities, and the level widths for different elements are important because of their wide use in atomic, molecular, and radiation physics, material science, environmental science, agriculture, forensic science, dosimetric computations for health physics, cancer therapy, elemental analysis, and basic studies of nuclear physics.

A vacancy in the inner shell of an atom is produced by various methods; photoionization is one of them. In this method, the incident gamma photon ejects the element electron to the continuum state, creating a vacancy in the inner shell. The fluorescence yield of an atomic shell or subshell is defined as the probability that a vacancy in that shell or subshell is filled through a radiative transition or a nonradiative transition.

In recent years, several attempts have been made for measuring X-ray fluorescence cross sections and yields for different elements. Krause et al. [1] have calculated theoretical K and L XRF cross sections. Puri et al. [2] published an extensive table of $\mathrm{K}$ shell $\mathrm{X}$-ray fluorescence cross sections for some elements in the energy range $1-200 \mathrm{keV}$. Bennal et al.
[3] measured K X-ray fluorescence parameters for Ag, Cd, In, and Sn elements. Seven [4] has measured photon induced K X-ray cross sections for some heavy elements. Hubbell et al. [5] have collected more recent experimental values of $\sigma_{\mathrm{K}_{i}}$. Theoretical values of $\sigma_{\mathrm{K}_{i}}$ were obtained in the region $44 \leq Z \leq 54$ by McGuire [6, 7]. Chen et al. [8] used a Dirac-Hartree-Slater approach to calculate the $\sigma_{\mathrm{K}}$ values of elements in the atomic range $18 \leq Z \leq 96$. Bambynek et al. [9] have fitted their collection of selected most reliable experimental values of $\sigma_{\mathrm{K}}$ in the $13 \leq Z \leq 92$ range. The $\mathrm{K}_{\alpha}, \mathrm{K}_{\beta}$, and total $\mathrm{KX}$-rays fluorescence cross sections and the average fluorescence yields for six elements with $16 \leq Z \leq 23$ at $5.96 \mathrm{keV}$ have been measured by Sahin et al. [10]. Horakeri et al. $[11,12]$ determined $\mathrm{K}$ shell fluorescence yields by using a simple method for some elements in $62 \leq Z \leq 83$ at 123.6 and $320 \mathrm{keV}$ energies. Pious et al. [13] determined total $\mathrm{K}$ fluorescence yields by using Xe filled proportional counter for some low elements at $59.5 \mathrm{keV}$. Balakrishna et al. [14] measured K fluorescence yields using HPGe low energy photon detector for some rare earth and heavy elements with 59.5 and $279.2 \mathrm{keV}$ gamma rays.

Rao et al. [15] showed that the $\mathrm{K}_{\beta} / \mathrm{K}_{\alpha}$ intensity ratios depend on the excitation modes in $3 \mathrm{D}$ elements, but they could not find such dependence for the high $Z$ elements. Dhal and Padhi [16] have investigated relative K X-ray intensities 
on the elements from $\mathrm{Mn}$ to $\mathrm{Sb}$ using $59.5 \mathrm{keV}$ gamma rays. Rebohle et al. [17] have measured $\mathrm{K}_{\beta} / \mathrm{K}_{\alpha}$ intensity ratio for pure $3 \mathrm{D}$ elements. Similarly, Ertuğrul et al. [18] have measured $\mathrm{K}_{\beta} / \mathrm{K}_{\alpha}$ intensity ratios in element range $22 \leq Z \leq$ 69 at $59.5 \mathrm{keV}$. Pawlowski et al. [19] have reported the valence electronic structure of $\mathrm{Ti}, \mathrm{Cr}, \mathrm{Fe}$, and $\mathrm{Co}$ in some alloys from $\mathrm{K}_{\beta} / \mathrm{K}_{\alpha} \mathrm{X}$-ray intensity ratios. The vacancy transfer probabilities from $\mathrm{K}$ to $\mathrm{L}$ shell $\eta_{\mathrm{KL}}$ were obtained by measuring the $\mathrm{K}_{\beta} / \mathrm{K}_{\alpha}$ intensity ratios in 25 elements over the range $57 \leq$ $Z \leq 92$ using a $25 \mathrm{mCi}^{57} \mathrm{Co}$ filtered source for excitation and a $\mathrm{Si}$ (Li) detector by Ertugral et al. [20]. Santra et al. [21] have measured $\mathrm{K}$ to $\mathrm{L}$ shell vacancy transfer probabilities of Mo, $\mathrm{Pd}$, and $\mathrm{Cd}$ by exciting them with the $\mathrm{K} \mathrm{X}$-rays of $\mathrm{Ni}$ and Sn induced by the bremsstrahlung emanating from an X-ray tube. Demir and Şahin [22] have measured K shell X-ray production cross sections and fluorescence yields for Nd, Eu, Gd, Dy, and Ho using radioisotope in the external magnetic field.

The aim of this study is to determine the production cross sections $\sigma_{\mathrm{K}_{i}}$, the fluorescence yield $w_{\mathrm{K}}$, K shell X-ray intensity ratio $I_{\mathrm{K}_{\beta}} / I_{\mathrm{K}_{\alpha}}$, the vacancy transfer probabilities from $\mathrm{K}$ to $\mathrm{L}$ shell $\eta_{\mathrm{KL}}$, and the $\Gamma_{\mathrm{K}}$ level widths for some elements in the atomic range $40 \leq Z \leq 50$. The samples were excited by $80.998 \mathrm{keV}$ gamma rays from a $10 \mathrm{mCi}{ }^{133} \mathrm{Ba}$ radioactive source. The $\mathrm{K}$ X-rays emitted by samples were detected by using a CdTe detector.

\section{Experimental Procedure}

The experimental setup and the geometry used in the measurements are shown in Figure 1.

All samples were irradiated with $80.998 \mathrm{keV}$ gamma rays from a $10 \mathrm{mCi}{ }^{133} \mathrm{Ba}$ radioactive source. The samples were placed at a $45^{\circ}$ angle with respect to the direct beam, and fluorescent X-rays emitted at $90^{\circ}$ to the direct beam were detected by the collimated CdTe detector. An AMPTEK XR$100 \mathrm{~T}-\mathrm{CdTe}$ detector of crystal dimensions $3 \times 3 \times 1 \mathrm{~mm}^{3}$ was used in this work. A $250 \mu \mathrm{m}$ Be window is in front of the detector. The characteristic properties of CdTe detector are given in Table 1 .

The preamp signals were processed by Ampteks digital processors, including PX4, DP4, and X123, using trapezoidal shaping and no rise-time discrimination. The digital processors include a multichannel analyzer, power supplies, closed-loop temperature regulation, and the bias voltage for the detector. The data were taken at $224 \mathrm{~K}$ and at $502 \mathrm{~V}$ bias. The data were acquired by the ADMCA.EXE software provided with Amptek's digital processors. Spectrum analysis was carried out using the XRFFP software, developed jointly by Amptek and by Cross Roads Scientific. Special analysis algorithms have been developed for CdTe, which are incorporated with the commercially available package. The background spectra were measured in the laboratory, using a lead filter with a thickness of $30 \mathrm{~mm}$. It was observed that the background level in the lead filter is smaller than that in a room. Thus, the detector was shielded by a filter of lead to obtain a thin beam of photons and to prevent undesirable radiation. The output from the preamplifier, with pulse pileup rejection capability, was fed to a multichannel analyzer

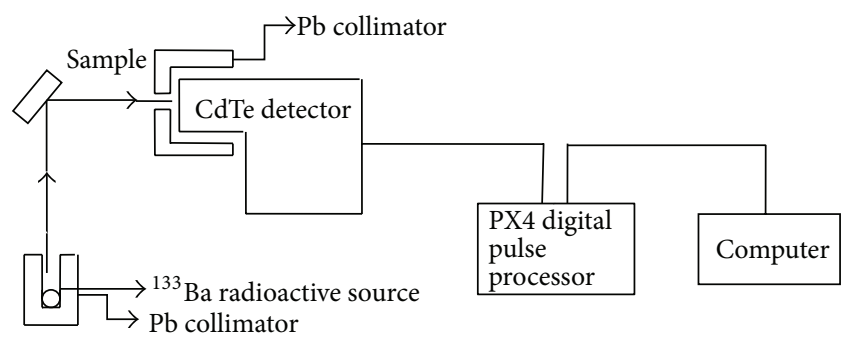

FIGURE 1: The experimental setup.

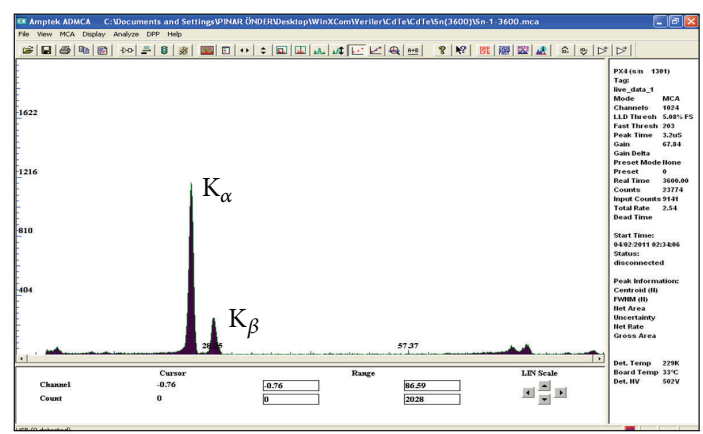

Figure 2: Typical K X-rays spectrum of Sn target.

interfaced with a personal computer provided with suitable software for data acquisition and peak analysis. The mean of ten channels at each side of the peaks was used to calculate the background and to define the net peak area. The peak areas were determined after the peaks were fitted either with pure Gaussians or Gaussians with exponential tails using the Microcal Origin 7.5 Software. A typical K shell X-ray spectrum of Sn target is shown in Figure 2.

The experimental production cross sections $\sigma_{\mathrm{K}_{i}}$ were evaluated using the relation

$$
\sigma_{\mathrm{K}_{i}}=\frac{N_{\mathrm{K}_{i}}}{I_{0} G \varepsilon_{\mathrm{K}_{i}} \beta_{\mathrm{K}_{i}} m} \quad(i=\alpha, \beta),
$$

where $N_{\mathrm{K}_{i}}$ is the measured intensity, $I_{0}$ is intensity of incident radiation, $G$ is a geometrical factor, $\varepsilon_{\mathrm{K}_{i}}$ is the efficiency of the detector at the average KX-ray energy of the element, $m$ is the mass per unit area of the element in $\mathrm{g} / \mathrm{cm}^{2}$, and $\beta_{\mathrm{K}_{i}}$ is the selfabsorption correction for the target material, which accounts for the absorption in the sample of the incident photons and the emitted characteristic X-rays. The values of $\beta_{\mathrm{K}_{i}}$ have been calculated by using the following expression:

$$
\beta_{\mathrm{K}_{i}}=\frac{1-\exp \left[-\left(\mu_{1} / \sin \theta+\mu_{2} / \sin \phi\right) m\right]}{\left(\mu_{1} / \sin \theta+\mu_{2} / \sin \phi\right) m},
$$

where $\mu_{1}$ and $\mu_{2}$ are the mass attenuation coefficients (from [26]) of incident photons and emitted characteristic X-rays, respectively; the angles of the incident photons and emitted $\mathrm{X}$-rays with respect to the surface of samples are $\theta$ and $\phi$, respectively.

The value of the factors $I_{0} G \varepsilon_{\mathrm{K}_{i}}$, which contain terms related to the incident photon flux, geometrical factor, and the 
TABLE 1: The characteristic properties of CdTe detector.

\begin{tabular}{lccccccc}
\hline $\begin{array}{l}\text { Atomic } \\
\text { number }\end{array}$ & Density, $\mathrm{g} / \mathrm{cm}^{3}$ & Band gap, eV & $\begin{array}{c}\text { Average electron-hole } \\
\text { pair eV }\end{array}$ & $\begin{array}{c}\text { Average electron-hole pair Mobility } \\
\text { at } 25^{\circ} \mathrm{C}, \mathrm{cm}^{2} /(\mathrm{V} \cdot \mathrm{sec}), \mathrm{eV} \\
n^{*}\end{array}$ & $p^{*}$ & $\begin{array}{c}\text { Average lifetime, sec } \\
n^{*}\end{array}$ \\
\hline 48.5 & 6.06 & 1.47 & 4.43 & 1100 & 100 & $10^{-6}$ & $10^{-7}$ \\
\hline
\end{tabular}

efficiency of the detector, was determined by collecting the $\mathrm{K}$ $\mathrm{X}$-ray spectra of thin samples of $\mathrm{Zr}, \mathrm{Nb}, \mathrm{Mo}, \mathrm{Ru}, \mathrm{Rh}, \mathrm{Pd}, \mathrm{Ag}$, $\mathrm{Cd}$, and Sn with the mass thickness $0.031-0.865 \mathrm{~g} / \mathrm{cm}^{2}$ in the same geometry and using the following equation:

$$
I_{0} G \varepsilon_{\mathrm{K}_{i}}=\frac{N_{\mathrm{K}_{i}}}{\sigma_{\mathrm{K}_{i}} m \beta_{\mathrm{K}_{i}}},
$$

where $N_{\mathrm{K}_{i}}$ is the net number of counts under the corresponding photopeak, $m_{i}$ is the thickness of target in $\mathrm{g} / \mathrm{cm}^{2}$, and $\beta_{\mathrm{K}_{i}}$ is the self-absorption correction factor for the target material, which accounts for the absorption in the target of the incident photons and the emitted characteristic X-rays. The theoretical production cross sections $\sigma_{\mathrm{K}_{i}}$ were evaluated using the relation

$$
\sigma_{\mathrm{K}_{i}}=\sigma_{\mathrm{K}} \omega_{\mathrm{K}} f_{\mathrm{K}_{i}} \text {, }
$$

where $\sigma_{\mathrm{K}}$ is the $\mathrm{K}$ shell photoionization cross section for the given elements at the excitation energy $E$. The values of $\sigma_{\mathrm{K}}$ used in these calculations were taken from the report by Scofield [27]. $w_{\mathrm{K}}$ is the $\mathrm{K}$ shell fluorescence yield. The values of $w_{\mathrm{K}}$ were taken from the annotated bibliography of Krause [23]. $f_{\mathrm{K}_{i}}$ is the fractional X-ray emission rate for $\mathrm{K}_{i} \mathrm{X}$-rays taken from Scofield [24].

The semiempirical $\mathrm{K}$ shell fluorescence yields $w_{\mathrm{K}}$ were measured according to the following equation:

$$
\omega_{\mathrm{K}}=\frac{\sigma_{\mathrm{K}}}{\sigma_{\mathrm{K}}(E)},
$$

where $\sigma_{\mathrm{K}}$ is the total $\mathrm{K} \mathrm{X}$-ray fluorescence cross section obtained experimentally and $\sigma_{\mathrm{K}}(E)$ is the theoretical $\mathrm{K}$ shell photoionization cross section of a given element for the excitation energy $E$ [27].

The experimental $\mathrm{K}$ shell $\mathrm{X}$-ray intensity ratios $I_{\mathrm{K}_{\beta}} / I_{\mathrm{K}_{\alpha}}$ were evaluated using the equation

$$
\frac{I_{\mathrm{K}_{\beta}}}{I_{\mathrm{K}_{\alpha}}}=\frac{N\left(\mathrm{~K}_{\beta}\right)}{N\left(\mathrm{~K}_{\alpha}\right)} \frac{\beta\left(\mathrm{K}_{\alpha}\right)}{\beta\left(\mathrm{K}_{\beta}\right)} \frac{\varepsilon\left(\mathrm{K}_{\alpha}\right)}{\varepsilon\left(\mathrm{K}_{\beta}\right)},
$$

where $N\left(\mathrm{~K}_{\alpha}\right)$ and $N\left(\mathrm{~K}_{\beta}\right)$ are net counts observed under the peaks corresponding to $\mathrm{K}_{\alpha}$ and $\mathrm{K}_{\beta} \mathrm{X}$-rays, respectively, $\beta\left(\mathrm{K}_{\alpha}\right)$ and $\beta\left(\mathrm{K}_{\beta}\right)$ are the sample self-absorption correction factors for the incident photon and emitted $\mathrm{KX}$-rays photons, and $\varepsilon\left(\mathrm{K}_{\alpha}\right)$ and $\varepsilon\left(\mathrm{K}_{\beta}\right)$ are photopeak efficiency values of the detector.

The experimental $\mathrm{K}$ to $\mathrm{L}$ shell total vacancy transfer probabilities $\eta_{\mathrm{KL}}$ were calculated by using the following equation [28]:

$$
\eta_{\mathrm{KL}}=\frac{2-\omega_{\mathrm{K}}}{1+\left(I_{\mathrm{K}_{\beta}} / I_{\mathrm{K}_{\alpha}}\right)},
$$

TABLE 2: The experimental $\sigma_{\mathrm{K}_{\alpha}}$ and $\sigma_{\mathrm{K}_{\beta}}$ production cross sections.

\begin{tabular}{lcccc}
\hline Sample & $\begin{array}{c}\text { Experimental } \\
\sigma_{\mathrm{K}_{\alpha}}\end{array}$ & $\begin{array}{c}\text { Theoretical } \\
\sigma_{\mathrm{K}_{\alpha}}\end{array}$ & $\begin{array}{c}\text { Experimental } \\
\sigma_{\mathrm{K}_{\beta}}\end{array}$ & $\begin{array}{c}\text { Theoretical } \\
\sigma_{\mathrm{K}_{\beta}}\end{array}$ \\
\hline $\mathrm{Zr}$ & 118.374 & 118.374 & 20.561 & 20.562 \\
$\mathrm{Nb}$ & 137.257 & 137.257 & 24.322 & 24.322 \\
$\mathrm{Mo}$ & 148.251 & 148.252 & 26.818 & 26.819 \\
$\mathrm{Ru}$ & 172.576 & 172.577 & 32.358 & 32.358 \\
$\mathrm{Rh}$ & 202.336 & 202.336 & 38.565 & 38.565 \\
$\mathrm{Pd}$ & 222.744 & 222.745 & 43.056 & 43.057 \\
$\mathrm{Ag}$ & 244.202 & 244.203 & 47.961 & 47.961 \\
$\mathrm{Cd}$ & 267.368 & 267.369 & 55.016 & 53.340 \\
$\mathrm{Sn}$ & 316.684 & 316.685 & 64.274 & 65.269 \\
\hline
\end{tabular}

where $\omega_{\mathrm{K}}$ is the fluorescence yield and $I_{\mathrm{K}_{\beta}} / I_{\mathrm{K}_{\alpha}}$ is the intensity ratio of the $\mathrm{K} \mathrm{X}$-rays. The $\mathrm{K}$ level width was measured using the following relation:

$$
\Gamma_{\mathrm{K}}=\frac{\Gamma_{\mathrm{K}}(R)}{w_{\mathrm{K}}}
$$

where $\Gamma_{\mathrm{K}}(R)$ is the radiative transition rate.

\section{Results and Discussion}

The overall error in the present measurements is estimated to be $4-5 \%$. This error is the quadrature sum of the uncertainties in the different parameters used to evaluate the $\mathrm{K}$ shell fluorescence parameters, that is, target thickness $(\leq 1 \%)$, the evaluation of the peak area $(\leq 3 \%)$, detector efficiency $I_{0} G \varepsilon_{K_{i j}}$ $(\leq 3 \%)$, and absorption correction factor $(\leq 2 \%)$.

The experimental values of $\sigma_{\mathrm{K}_{\alpha}}$ and $\sigma_{\mathrm{K}_{\beta}}$ production cross sections in the atomic range $40 \leq Z \leq 50$ for $80.998 \mathrm{keV}$ are listed in Table 2 . The $\sigma_{\mathrm{K}_{\alpha}}$ and $\sigma_{\mathrm{K}_{\beta}}$ production cross sections versus atomic number were plotted in Figures 3 and 4, also.

These theoretical values were calculated by using $\mathrm{K} \mathrm{X}$ ray emission rates based on relativistic Hartree-Slater theory [24]. The present experimental results of $\mathrm{K}$ shell X-ray production cross sections are only compared with the calculated theoretical values. The deviations between the theoretical and experimental values are found to be $0.0006 \%$ and $3 \%$ for $\sigma_{\mathrm{K}_{\alpha}}$ and $\sigma_{\mathrm{K}_{\beta}}$, respectively. The reason for larger deviation between the experimental and the theoretical values for $\sigma_{\mathrm{K}_{\alpha}}$ is statistically poor due to lower intensity of the $\mathrm{K}_{\beta}$ line in comparison with the $\mathrm{K}_{\alpha}$ line.

The $\mathrm{K}$ shell fluorescence yields $\omega_{\mathrm{K}}$ for these elements were calculated and listed in Table 3 together with theoretical values. The theoretical values were taken from Krause [23]. 


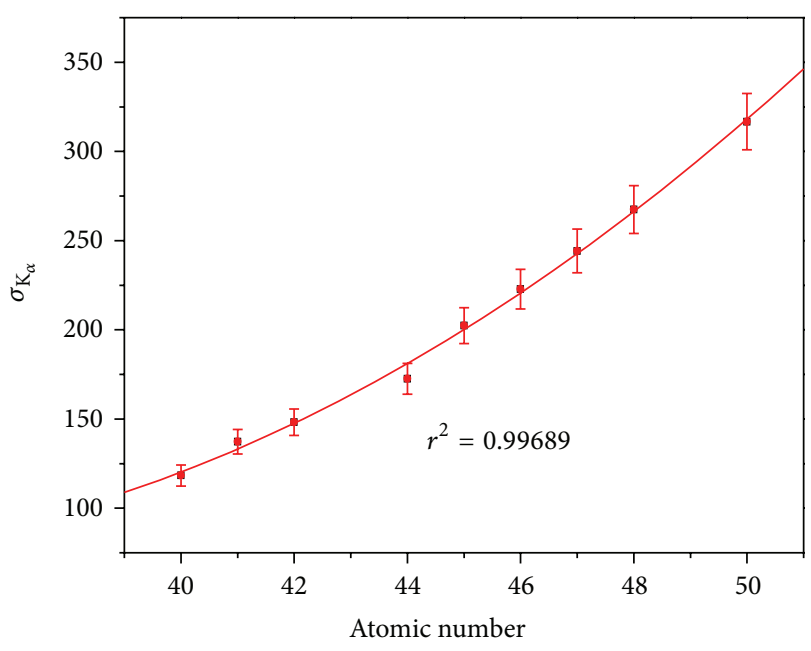

- Theo

- Exp.

FIGURE 3: The variation in $\sigma_{\mathrm{K}_{\alpha}}$ production cross sections as a function of atomic number.

TABLE 3: K shell X-ray fluorescence yields.

\begin{tabular}{lcc}
\hline Sample & $w_{\mathrm{K}}$ experimental & Krause (1979) [23] \\
\hline $\mathrm{Zr}$ & 0.730 & 0.730 \\
$\mathrm{Nb}$ & 0.747 & 0.747 \\
$\mathrm{Mo}$ & 0.765 & 0.765 \\
$\mathrm{Ru}$ & 0.749 & 0.749 \\
$\mathrm{Rh}$ & 0.808 & 0.808 \\
$\mathrm{Pd}$ & 0.820 & 0.820 \\
$\mathrm{Ag}$ & 0.831 & 0.831 \\
$\mathrm{Cd}$ & 0.847 & 0.843 \\
$\mathrm{Sn}$ & 0.859 & 0.862 \\
\hline
\end{tabular}

The average $\mathrm{K}$ shell fluorescence yields are plotted as function of the atomic number in Figure 5, also. Our experimental values have differences of $0.35-0.47 \%$ with Krause [23]. This may be due to the fact that when the elements of K X-ray energies increase, the detector efficiency decreases.

The experimental values of $I_{\mathrm{K}_{\beta}} / I_{\mathrm{K}_{\alpha}} \mathrm{X}$-ray intensity ratios for these elements were calculated from (6) and listed in Table 4. The experimental values of the $I_{\mathrm{K}_{\beta}} / I_{\mathrm{K}_{\alpha}}$ intensity ratios are plotted as a function of the atomic number in Figure 6. As seen from Figure 6 , the $I_{\mathrm{K}_{\beta}} / I_{\mathrm{K}_{\alpha}} \mathrm{X}$-ray intensity ratios increase evidently with increase in atomic number. The experimental $I_{\mathrm{K}_{\beta}} / I_{\mathrm{K}_{\alpha}}$ intensity ratios are also in agreement with the theoretical values calculated for these elements as given in Table 4. Our experimental values have differences of $0.5-3 \%$ with Scofield's [24].

The experimental values of $\eta_{\mathrm{KL}}$ were calculated from (7), listed in Table 5, and plotted as a function of the atomic number in Figure 7. The values of the $\eta_{\mathrm{KL}}$ decrease with the increase in atomic numbers. $\mathrm{K}$ shell electrons of $\mathrm{Zr}, \mathrm{Nb}$, $\mathrm{Mo}, \mathrm{Ru}, \mathrm{Rh}, \mathrm{Pd}, \mathrm{Ag}, \mathrm{Cd}$, and Sn were excited by using the radioisotope source since $\mathrm{K}$-edges energie of these elements

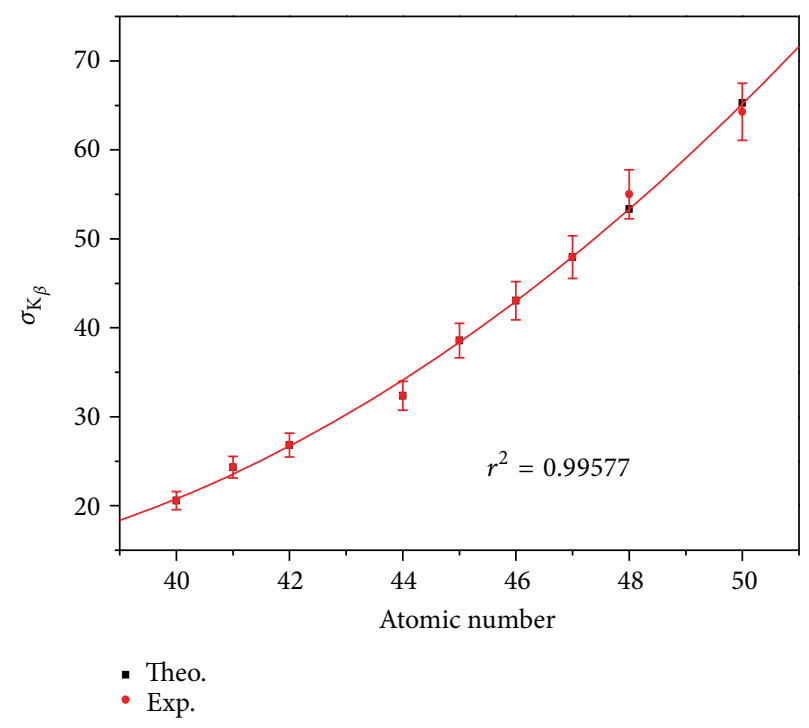

FIGURE 4: The variation in $\sigma_{\mathrm{K}_{\beta}}$ production cross sections as a function of atomic number.

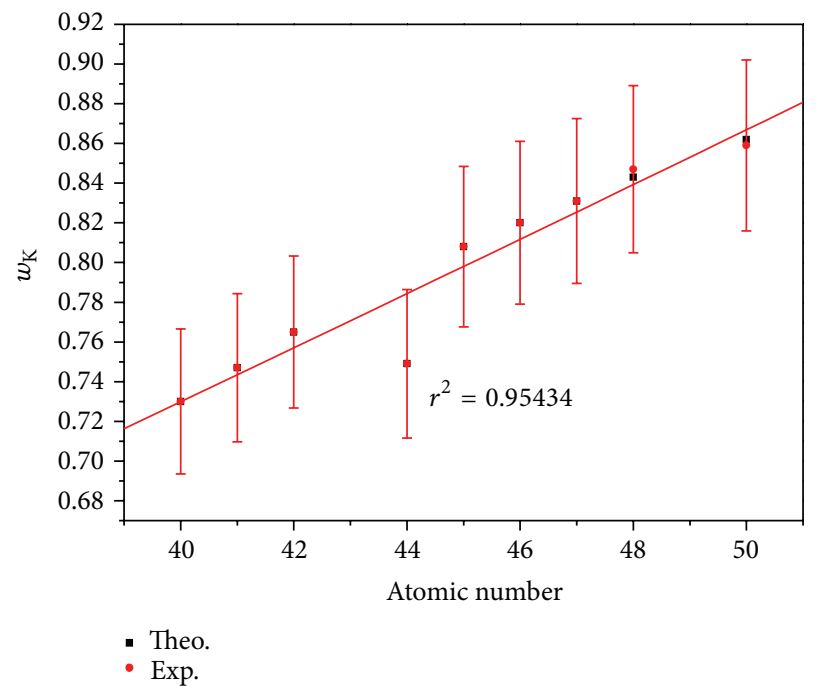

FIGURE 5: K X-ray fluorescence yields versus atomic number.

are lower than the energy of the incident photons. The vacancy created in the $\mathrm{K}$ shell is filled through the radiative transition or a nonradiative transition. Since the L X-ray intensity is enhanced with the $\mathrm{K}$ to $\mathrm{L}$ shell vacancy transfer, the $\mathrm{L}$ X-ray production cross sections of $\mathrm{Zr}, \mathrm{Nb}, \mathrm{Mo}, \mathrm{Ru}$, $\mathrm{Rh}, \mathrm{Pd}, \mathrm{Ag}, \mathrm{Cd}$, and Sn increase. As seen from Table 5, the experimental values of $\eta_{\mathrm{KL}}$ agree with the theoretically calculated values within $0.3-5 \%$

The experimental values of $\Gamma_{\mathrm{K}}$ were calculated from (8), listed in Table 6 and plotted as a function of the atomic number in Figure 8. Our experimental values have differences of $0.2-0.5 \%$ with [25].

As a result, more experimental and theoretical values for the elements from $\mathrm{Zr}$ to $\mathrm{Sn}$ are needed for full knowledge of $\mathrm{K} \mathrm{X}$-ray fluorescence parameters. These experimental values 


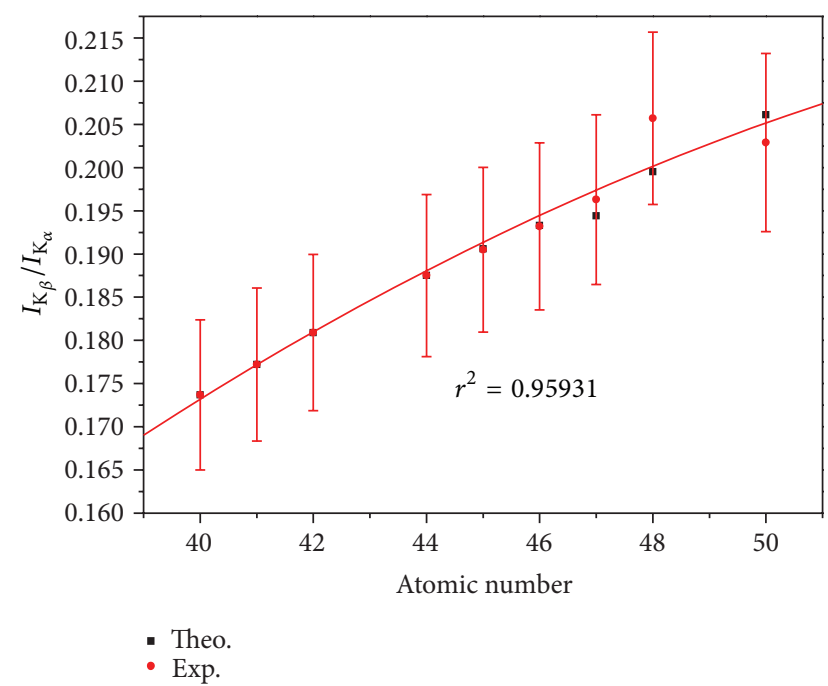

FIGURE 6: The variation in $I_{\mathrm{K}_{\beta}} / I_{\mathrm{K}_{\alpha}}$ as a function of atomic number.

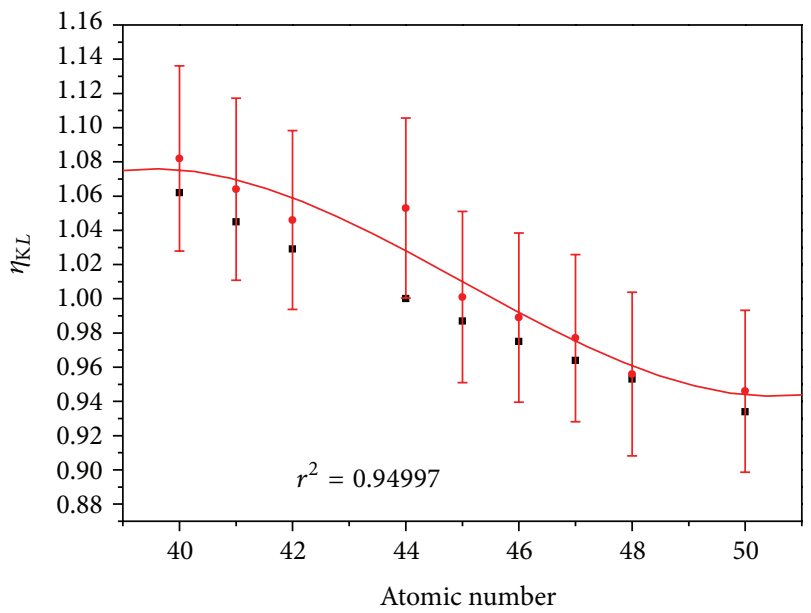

- Theo.

- Exp.

FIGURE 7: The variation in $\eta_{\mathrm{KL}}$ as a function of atomic number.

TABLE $4: I_{\mathrm{K}_{\beta}} / I_{\mathrm{K}_{\alpha}} \mathrm{X}$-ray intensity ratios.

\begin{tabular}{lcc}
\hline Sample & $I_{\mathrm{K}_{\beta}} / I_{\mathrm{K}_{\alpha}}$ experimental & Scofield (1974) [24] \\
\hline $\mathrm{Zr}$ & 0.1737 & 0.1737 \\
$\mathrm{Nb}$ & 0.1772 & 0.1772 \\
$\mathrm{Mo}$ & 0.1809 & 0.1809 \\
$\mathrm{Ru}$ & 0.1875 & 0.1875 \\
$\mathrm{Rh}$ & 0.1905 & 0.1906 \\
$\mathrm{Pd}$ & 0.1932 & 0.1933 \\
$\mathrm{Ag}$ & 0.1963 & 0.1944 \\
$\mathrm{Cd}$ & 0.2057 & 0.1995 \\
$\mathrm{Sn}$ & 0.2029 & 0.2061 \\
\hline
\end{tabular}

are very important for qualitative and quantitative element analysis used in the XRF technique. It is well known that characteristic X-ray lines are influenced by the chemical state

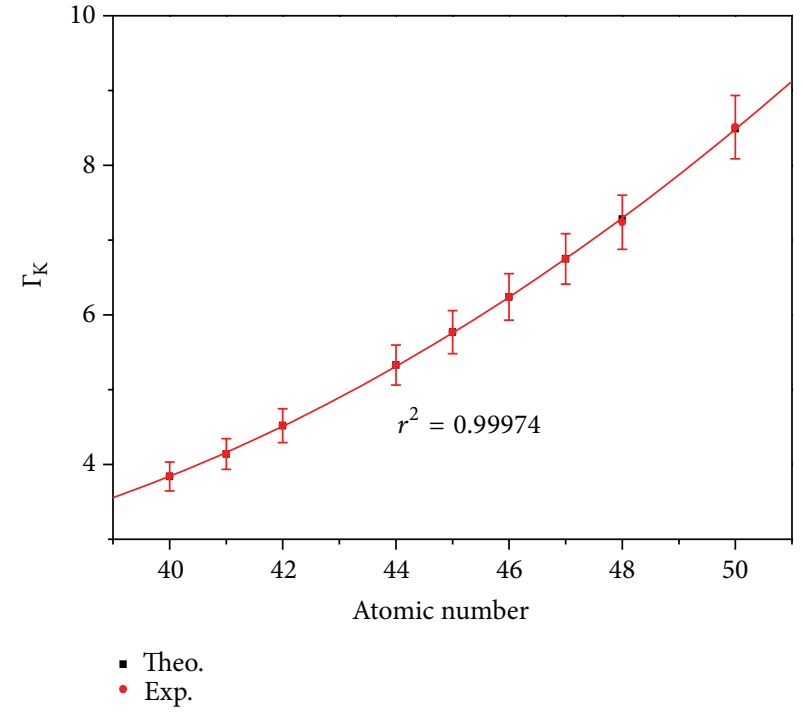

Figure 8: The variation in $\Gamma_{\mathrm{K}}$ as a function of atomic number.

TABLE 5: K-L total vacancy transfer.

\begin{tabular}{lcc}
\hline Sample & $\eta_{\mathrm{KL}}$ experimental & Theoretical \\
\hline $\mathrm{Zr}$ & 1.082 & 1.062 \\
$\mathrm{Nb}$ & 1.064 & 1.045 \\
$\mathrm{Mo}$ & 1.046 & 1.029 \\
$\mathrm{Ru}$ & 1.053 & 1.000 \\
$\mathrm{Rh}$ & 1.001 & 0.987 \\
$\mathrm{Pd}$ & 0.989 & 0.975 \\
$\mathrm{Ag}$ & 0.977 & 0.964 \\
$\mathrm{Cd}$ & 0.956 & 0.953 \\
$\mathrm{Sn}$ & 0.946 & 0.934 \\
\hline
\end{tabular}

TABLE 6: K shell $\Gamma_{\mathrm{K}}$ level widths.

\begin{tabular}{lcc}
\hline Sample & $\Gamma_{\mathrm{K}}$ experimental & Krause and Oliver (1979) [25] \\
\hline $\mathrm{Zr}$ & 3.84 & 3.84 \\
$\mathrm{Nb}$ & 4.14 & 4.14 \\
$\mathrm{Mo}$ & 4.52 & 4.52 \\
$\mathrm{Ru}$ & 5.33 & 5.33 \\
$\mathrm{Rh}$ & 5.77 & 5.77 \\
$\mathrm{Pd}$ & 6.24 & 6.24 \\
$\mathrm{Ag}$ & 6.75 & 6.75 \\
$\mathrm{Cd}$ & 7.24 & 7.28 \\
$\mathrm{Sn}$ & 8.51 & 8.49 \\
\hline
\end{tabular}

of the emitting element: peak energy, peak width, relative emission rates, and satellite peak formation. Also, they are affected by the detected element speciation [29]. Thus, the obtained data can be helpful for the radioisotope XRF method for elemental analysis. 


\section{References}

[1] M. O. Krause, C. W. Nestor, C. J. Sparks, and E. Ricci, "X-ray fluorescence cross-sections for K and L rays of the elements," Tech. Rep. ORNL-5399, Review of Oak Ridge National Lab, 1978.

[2] S. Puri, B. Chand, D. Mehta, M. L. Garg, N. Singh, and P. N. Trehan, "K and L shell X-ray fluorescence cross sections," Atomic Data and Nuclear Data Tables, vol. 61, no. 2, pp. 289-311, 1995.

[3] A. S. Bennal, P. D. Shidling, N. M. Badiger, S. R. Thontadarya, and B. Hanumaiah, "Measurements of K x-ray fluorescence parameters," American Journal of Physics, vol. 73, no. 9, pp. 883887, 2005.

[4] S. Seven, "Measurement of photon-induced K X-rays production cross sections for elements with $62 \leq \mathrm{Z} \leq 74$," Turkish Journal of Physics, vol. 26, no. 6, pp. 483-489, 2002.

[5] J. H. Hubbell, P. N. Trehan, N. Singh et al., "A review, bibliography, and tabulation of $\mathrm{K}, \mathrm{L}$ and hinger atomic shell X-ray fluorescence yields," Journal of Physical and Chemical Reference Data, vol. 23, pp. 339-364, 1994.

[6] E. J. McGuire, "K-shell auger transition rates and fluorescence yields for elements be-ar," Physical Review, vol. 185, no. 1, pp. 1-6, 1969.

[7] E. J. McGuire, "K-Shell Auger transition rates and fluorescence yields for elements Ar-Xe," Physical Review A, vol. 2, no. 2, pp. 273-278, 1970.

[8] M. H. Chen, B. Crasemann, and H. Mark, "Relativistic Kshell Auger rates, level widths, and fluorescence yields," Physical Review A, vol. 21, no. 2, pp. 436-441, 1980.

[9] W. Bambynek, B. Crasemann, R. W. Fink et al., "X-ray fluorescence yields, auger, and coster-kronig transition probabilities," Reviews of Modern Physics, vol. 44, no. 4, pp. 716-813, 1972.

[10] M. Şahin, L. Demir, and G. Budak, "Measurement of K X-ray fluorescence cross-sections and yields for $5.96 \mathrm{keV}$ photons," Applied Radiation and Isotopes, vol. 63, no. 1, pp. 141-145, 2005.

[11] L. D. Horakeri, B. Hanumaiah, and S. R. Thontadarya, "Method for the determination of K-shell fluorescence yields," X-Ray Spectrometry, vol. 26, no. 2, pp. 69-74, 1997.

[12] L. D. Horakeri, B. Hanumaiah, and S. R. Thontadarya, "Kshell fluorescence yields of medium and heavy elements using a simple method," X-Ray Spectrometry, vol. 27, no. 5, pp. 344-348, 1998.

[13] J. K. Pious, K. M. Balakrishna, L. Ligappa, and K. Siddappa, "Total K fluorescence yields for Fe, Cu, Zn, Ge and Mo," Journal of Physics B, vol. 25, pp. 1155-1158, 1992.

[14] K. M. Balakrishna, N. G. Nayak, L. Ligappa, and K. Siddappa, " $K$ fluorescence yield measurements in rare earth and heavy elements," Journal of Physics B, vol. 27, pp. 715-720, 1994.

[15] N. V. Rao, S. B. Reddy, G. Satyanarayana, and D. L. Sastry, " $\mathrm{K}_{\beta} / \mathrm{K}_{\alpha} \mathrm{X}$-ray intensity ratios," Physica, vol. 142 , no. 3, pp. 375$380,1986$.

[16] B. B. Dhal and H. C. Padhi, "Relative Kx-ray intensities in some selected elements between $\mathrm{Mn}$ and $\mathrm{Sb}$ following ionization by 59.54-keV rays," Physical Review A, vol. 50, no. 2, pp. 1096-1100, 1994.

[17] L. Rebohle, U. Lehnert, and G. Zschornack, " $\mathrm{K}_{\beta} / \mathrm{K}_{\alpha}$ intensity ratios and chemical effects of some 3d elements," X-Ray Spectrometry, vol. 25, no. 6, pp. 295-300, 1996.

[18] M. Ertuğrul, Ö. Söğüt, Ö. Şimşek, and E. Büyükkasap, "Measurement of $\mathrm{K}_{\beta} / \mathrm{K}_{\alpha}$ intensity ratios for elements in the range 22 $\leq \mathrm{Z} \leq 69$ at $59.5 \mathrm{keV}$,' Journal of Physics B, vol. 34, pp. 909-914, 2001.

[19] F. Pawlowski, M. Polasik, S. Raj, H. C. Padhi, and D. K. Basa, "Valence electronic structure of $\mathrm{Ti}, \mathrm{Cr}, \mathrm{Fe}$ and Co in some alloys from $\mathrm{K}_{\beta}$-to- $\mathrm{K}_{\alpha} \mathrm{X}$-ray intensity ratio studies," Nuclear Instruments and Methods in Physics Research B, vol. 195, no. 3-4, pp. 367-373, 2002.

[20] B. Ertugral, G. Apaydin, H. Baltas, U. Çevik, A. I. Kobya, and M. Ertugrul, "Measurement of vacancy transfer probabilities from $\mathrm{K}$ to L shell for high atomic number elements," Spectrochimica Acta B, vol. 60, no. 4, pp. 519-524, 2005.

[21] S. Santra, A. C. Mandal, D. Mitra, M. Sarkar, and D. Bhattacharya, "Measurement of the K to L shell vacancy transfer probabilities for Mo, Pd and Cd in photon impact," Radiation Physics and Chemistry, vol. 74, no. 5, pp. 282-287, 2005.

[22] D. Demir and Y. Şahin, "Measurements of K-shell X-ray production cross sections and $\mathrm{K}$ to $\mathrm{L}$ and $\mathrm{M}$-shell radiative vacancy transfer probabilities for $\mathrm{Nd}, \mathrm{Eu}, \mathrm{Gd}, \mathrm{Dy}$ and Ho at excitation with $59.5 \mathrm{keV}$ photons in an external magnetic field," $X$-Ray Spectrometry, vol. 36, no. 3, pp. 178-184, 2007.

[23] M. O. Krause, "Atomic radiative and radiationless yields for $\mathrm{K}$ and L shells," Journal of Physical Chemistry, vol. 8, pp. 307-327, 1979.

[24] J. H. Scofield, "Relativistic Hartree Slater values for K and L X ray emission rates," Atomic Data and Nuclear Data Tables, vol. 14, no. 2, pp. 121-137, 1974.

[25] M. O. Krause and J. H. Oliver, "Natural widths of atomic K and $\mathrm{L}$ levels, $\mathrm{K}_{\alpha} \mathrm{X}$-Ray lines and several KLL auger lines," Journal of Physical Chemistry, vol. 8, p. 329, 1979.

[26] M. J. Berger and J. H. Hubbell, "XCOM: Photon Cross Section Database (version 3.1)," National Institute of Standards and Technology, Gaithersburg, Md, USA, 2000, http://physics.nist .gov/xcom.

[27] J. H. Scofield, "Theoretical photoionization cross-sections from 1 to $1500 \mathrm{keV}$," Tech. Rep. UCRL 51326, Lawrence Livermore Laboratory, Livermore, Calif, USA, 1973.

[28] E. Schönfeld and H. Janben, "Evaluation of atomic shell data," Nuclear Instruments and Methods in Physics Research, vol. 369, pp. 527-533, 1996.

[29] R. E. Grieken and A. A. Markowicz, Handbook of X-Ray Spectrometry: Methods and Techniques, Marcel Dekker, New York, NY, USA, 1993. 


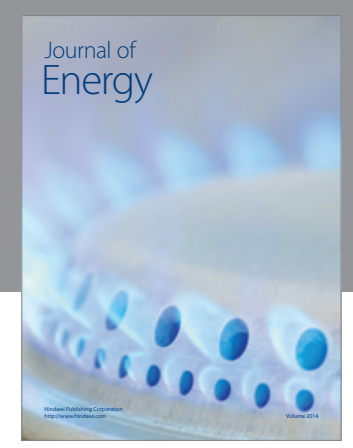

Journal of

Industrial Engineering
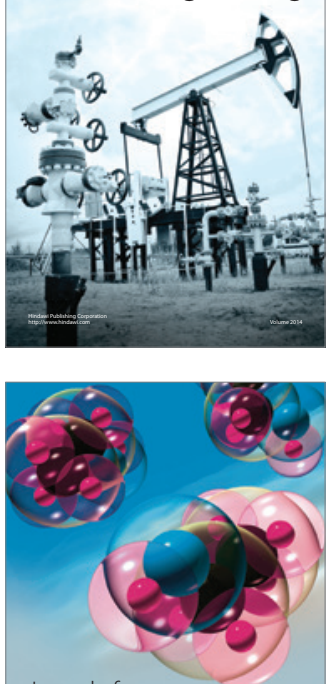

Fuels
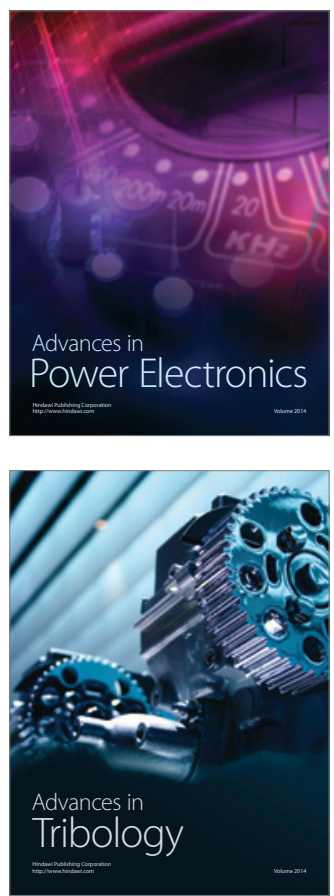

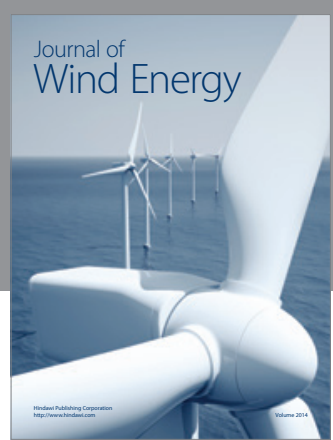

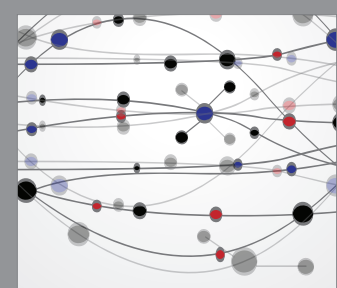

The Scientific World Journal

Submit your manuscripts at http://www.hindawi.com

Journal of

Structures
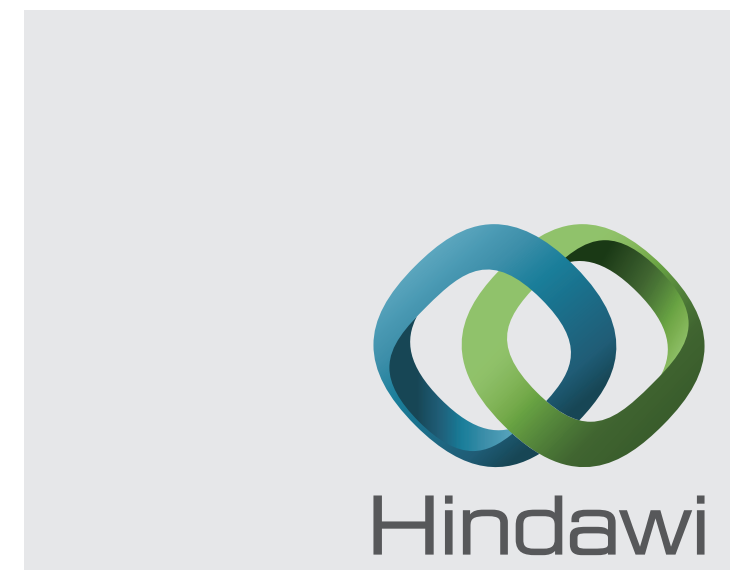

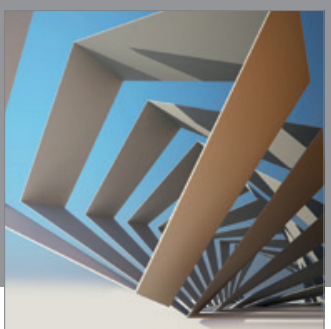

Rotating

Machinery
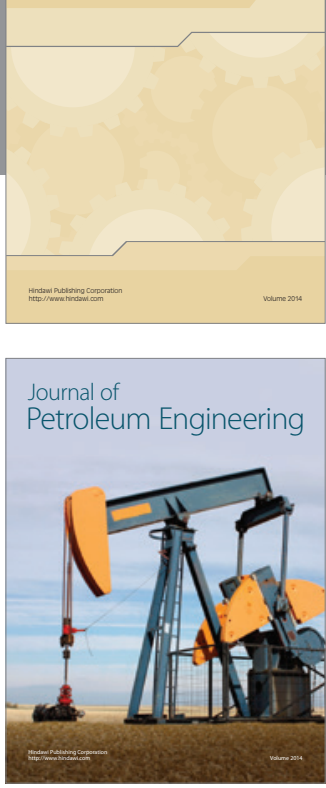

Journal of

Solar Energy
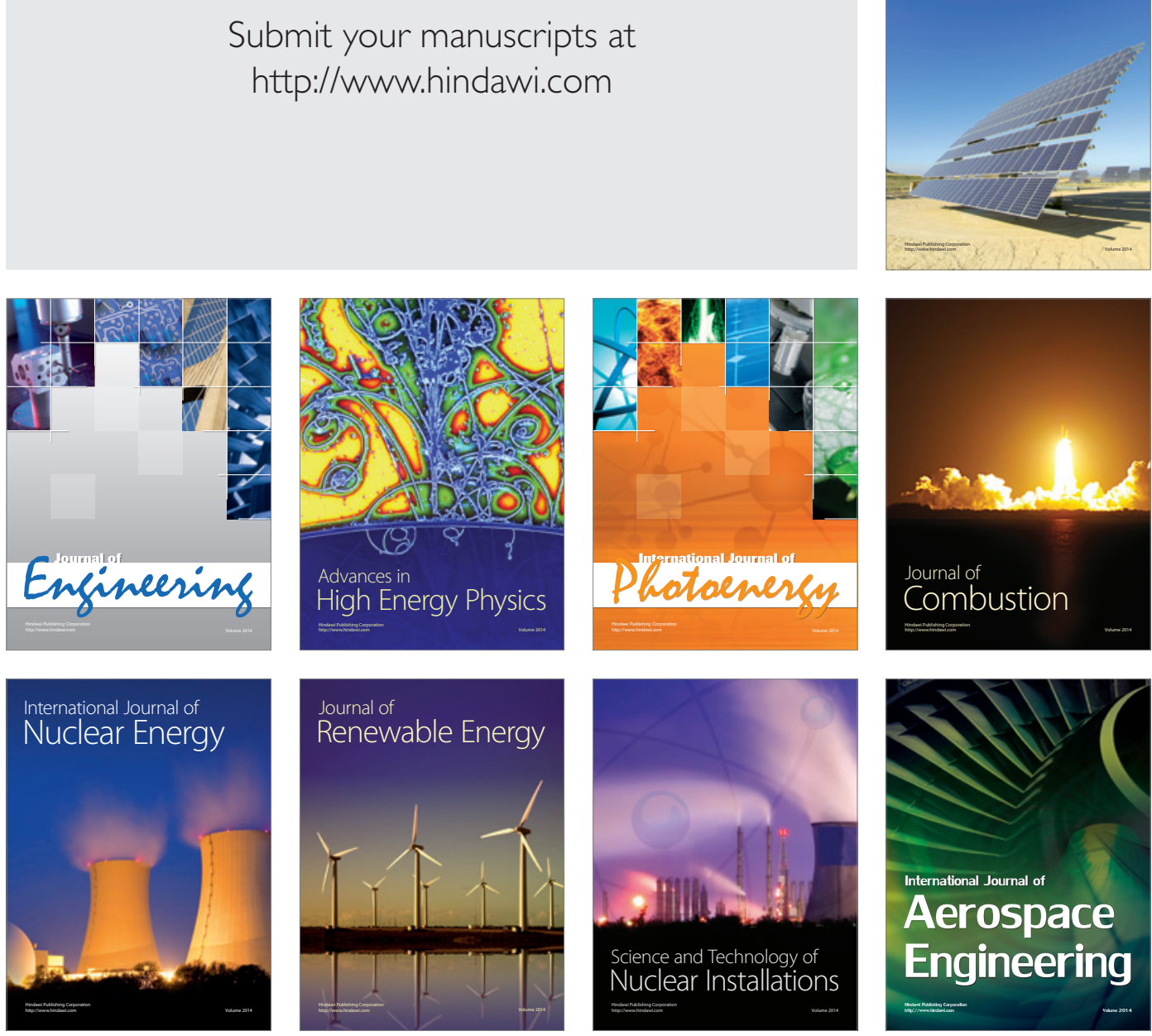